\title{
DNA-Related Pathways Defective in Human Premature Aging
}

\author{
Vilhelm A. Bohr \\ Laboratory of Molecular Gerontology, National Institute on Aging, National Institutes of \\ Health, 5600 Nathan Shock Dr., Baltimore, MD 21224 \\ E-mail: BohrV@grc.nia.gov
}

Received November 27, 2001; Revised March 18, 2002; Accepted March 20, 2002; Published May 7, 2002

One of the major issues in studies on aging is the choice of biological model system. The human premature aging disorders represent excellent model systems for the study of the normal aging process, which occurs at a much earlier stage in life in these individuals than in normals. The patients with premature aging also get the age associated diseases at an early stage in life, and thus age associated disease can be studied as well. It is thus of great interest to understand the molecular pathology of these disorders.

KEY WORDS: aging, premature aging, Werner syndrome, Cockayne syndrome, DNA repair

DOMAINS: aging, biochemistry, DNA repair, DNA metabolism

\section{HUMAN PREMATURE AGING DISORDERS}

A number of premature aging disorders have been described in humans. In patients with these disorders, aging-like symptoms and age-associated diseases appear much earlier than in the average normal individual; thus, the premature aging disorders are useful models for the study of the aging process. Werner syndrome (WS) is the most characterized premature aging disorder. Patients with WS have a large number of signs and symptoms of normal aging at a younger age than normal individuals. However, not all symptoms of WS resemble the normal aging process, and WS is best described as a segmental progeroid disorder. The premature aging disorders include the DNA-repair-defective disease xeroderma pigmentosum (XP), which includes seven complementation groups (separate genetic disorders). In this condition, the deficiency of the DNA repair pathway, nucleotide excision, leads to a severely increased incidence of cancer. In Cockayne syndrome, there is also a DNA repair defect, and in addition to the features of premature aging, these individuals have severe neurological deficits. Rothmund-Thompson syndrome, Hutchinson-Guilford, and progeria are other examples of this category of disorders. 
All of these diseases are very rare conditions in the general population. In several cases, the disorders are associated with a mutation in a single gene, which has by now been identified, cloned, and characterized. This means that molecular biochemical experimentation can be done. Complementation assays with transfected mutant cell lines or purified proteins added to extracts from mutant cell lines can be used to study the basis of molecular genetic defects.

\section{WERNER SYNDROME (WS) AND WERNER PROTEIN (WRNp)}

Werner syndrome (WS) is a homozygous recessive disease characterized by early onset of many aspects of normal aging, such as wrinkling of the skin, graying of the hair, cataracts, diabetes, and osteoporosis. Cancers, particularly sarcomas, have been seen in these patients with increased frequency. The symptoms of WS begin to appear around the age of puberty, and most patients die before age 50 .

WS is caused by mutations in a gene (WRN) belonging to the RecQ family of DNA helicases[1]. The WRN protein (WRNp) has been demonstrated biochemically to be a DNAunwinding enzyme by several laboratories[2,3], including ours (see below). The enzyme is a DNA-dependent ATPase and catalyzes strand displacement in a nucleotide-dependent reaction. WRNp has more than one enzymatic activity. It has recently been shown that it also has a 3'-5' exonuclease activity[4,5,6]. Thus, WRNp has helicase, exonuclease, and ATPase activities.

The precise molecular deficiencies involved in the clinical phenotypes of WS are only partially understood. The phenotypical changes are shown in Table 1. The well-documented genomic instability of WS may point to a defect in replication or recombination[7]. WS cells exhibit premature replicative senescence and delayed S-phase progression in some cell lines[8]. A defect in recombination is suggested by the hyper-recombinant phenotype observed in some WS cell lines. WS cell lines are also hypersensitive to drugs that cause DNA interstrand crosslinks[9,10]. These cross-links are repaired by recombinational pathways. Moreover, the WRN homologs in yeast, Sgs1 (Saccharomyces cerevisiae) and rqh1 (Schizosaccharomyces pombe), as well as the bacterial homolog $\operatorname{rec} Q$, all suppress illegitimate recombination[11]. WRNp, in vitro, also has antirecombinase activity[12]. Thus, there is evidence that WRNp functions as an antirecombinase.

Some evidence suggests a role for the WRNp in DNA repair. This notion is supported by a report that WS cells are sensitive to the carcinogen 4-nitroquinoline 1-oxide (4-NQO)[13]. However, WS cells do not exhibit hypersensitivity to UV light or other DNA-damaging agents, suggesting that a repair deficiency in WS is subtle and perhaps not the primary defect in the disease. A fine-structure DNA repair defect in lymphoblast but not fibroblast WS cell lines was reported by this laboratory using the gene-specific and strand-specific repair assays[14].

In addition to repair or replication defects, evidence from this laboratory suggests that WS cells are defective in transcription[15]. This laboratory hase used a variety of WS lymphoblast cell lines that carry homozygous mutations in the $W R N$ gene to assess the role of $W R N$ in transcription. Transcription was measured both in vivo, by $\left[{ }^{3} \mathrm{H}\right]-\mathrm{UTP}$ incorporation in the chromatin of permeabilized cells, and in vitro, by using a plasmid template with an RNA polymerase II-specific promoter. The transcription efficiency in different WS cell lines was found to be reduced to $40-60 \%$ of that observed in normal cells using both assays[15]. This defect can be complemented by the addition of normal cell extract to the chromatin of WS cells. Furthermore, the addition of purified WRNp to the in vitro transcription assay stimulates RNA polymerase II-driven transcription. These observations suggest that the WRNp may act as a general activator of RNA polymerase II transcription. 
TABLE 1

Cellular Defects in WS

Genomic instability

- Chromosomal rearrangements

- Large spontaneous deletions

Telomere maintenance

- Shortened telomeres

- SGS1 localization to telomeres

Recombination

- Hyper-recombination

Transcription

- RNA polymerase II transcription

Apoptosis

- Attenuated p53-mediated apoptosis
Replication

- Reduced replicative lifespan

- Extended S-phase

- Reduced frequency of initiation sites

DNA repair

- Hypersensitivity to 4-NQO

- Hypersensitivity to DNA cross-linking agents

- Reduced repair of psoralen cross-links

- Hypersensitivity to camptothecin

- Reduced telomeric repair

- Reduced transcription-coupled repair

Our laboratory and others[2,3] have demonstrated that WRN helicase can proficiently unwind short DNA duplexes ( $\sim 30$ bp) in a reaction dependent on nucleoside triphosphate hydrolysis. Unwinding of long DNA duplexes ( $\geq 250 \mathrm{bp})$ by WRN helicase is dependent on the presence of human Replication Protein A (RPA)[16].

\section{Werner Protein Interactions and Pathways}

In recent years there has been a great deal of interest in the functions of WRNp. Biochemical properties and interactions of WRNp have been studied. The clarification of these interactions is important in our quest to understand in which pathways and processes WRNp participates. A list of reported protein interactions is shown in Table 2. One of the first established physical and functional interactions of WRNp was with RPA[16]. As mentioned, RPA is required for WRNp to unwind large DNA duplexes. Since RPA participates in DNA replication and DNA repair, this suggests that WRNp may also participate in both of those processes. It was later observed that the tumor suppressor protein $\mathrm{p} 53$ also binds to $\mathrm{WRNp}[17]$, and p53 is, incidentally, known to interact with RPA. Evidence from this laboratory shows that the physical interaction between WRNp and p53 is also associated with a functional interaction. p53 inhibits the exonuclease activity of WRNp directly[18] and thus may have a function in its regulation. This may imply that these proteins participate in a common pathway. p53 is known to participate in various signal transduction pathways, particularly in cell cycle regulation and apoptosis. Interestingly, WS cells have an attenuated apoptosis process[17], supporting the notion that p53 and WRNp both participate in the apoptotic process.

There is evidence for a role of WRNp in DNA replication. WS cells have been noted to have a prolonged S-phase[8], and the WRNp has been identified as a component of the replication complex in mammalian cells[19]. In addition, recent studies have shown that WRNp binds to and stimulates one of the major DNA polymerases, DNA polymerase $\delta[20,21]$. WRNp also interacts physically with another replication protein, proliferating cell nuclear antigen (PCNA), and the functional consequence of this interaction is not yet understood. The previously discussed RPA interaction also supports the notion that WRNp functions in replication. Taken together with the observation that WS cells have prolonged S-phase, it is likely that WRNp plays an important role in replication. This could be by resolving complex DNA structures during replication or by affecting the mobility of replication forks after exposure of cells to DNA damage. 


\section{TABLE 2}

\section{WRN Protein Interactions}

\section{Physical interactions}

RPA

$\mathrm{Ku} 80 / 70$

p53

human polymerase $\delta$ ( $\mathrm{p} 50$ )

PCNA

Topoisomerase I

WHIP

Ubc9

FEN-1

\author{
(Brosh et al. 1999) \\ (Cooper et al, 2000; Li and Comai, 2000) \\ (Spillare et al., 1999;Blander et al., 1999) \\ (Szekely et al., 2000) \\ (Lebel et al., 1999) \\ (Lebel et al., 1999) \\ (Kawabe ef al. , 2000) \\ (Kawabe et al. 2000) \\ (Brosh et al., 2000)
}

\section{Functional Interactions}

$\begin{array}{lll}\text { RPA } & \text { Stimulates WRN helicase } & \text { (Shen et al., 1998;Brosh et al., 1999) } \\ \text { Ku 80/70 } & \text { Stimulates WRN exonuclease } & \text { (Cooper et al., 2000;Li and Comai, 2000) } \\ \text { p53 } & \text { Inhibits WRN exomuclease } & \text { (Brosh et al., 2001) } \\ \text { A polymerase } & \text { Stimulates DNA synthesis by yeast polo (Kamath-Loeb et al., 2000) } \\ \text { FEN-1 } & \text { Stimulates FEN-1 nuclease } & \text { (Brosh et al., in press) }\end{array}$

As mentioned above, WS cells have increased genomic instability, and this has led to much speculation about whether a DNA repair pathway might be defective in WS. Recombination, in general, occurs via two different pathways, one that is homologous (requiring sequence homology) and one that is not, nonhomologous end rejoining (NHEJ). WRNp interacts both physically and functionally with the Ku heterodimer protein[22], which is involved in NHEJ and also is localized at telomeric ends. Ku binds very strongly to WRNp, suggesting that this interaction represents an important pathway in WRNp functions. It then strongly stimulates the WRNp exonuclease activity[22]. WS cells are sensitive to agents that form DNA interstrand cross-links $[9,10]$, and these adducts in DNA are repaired by DNA recombination.

The biochemical steps of NHEJ specifically involve DNA helicase and exonuclease functions[23], and thus there is a need in this process for both of the catalytic functions of WRNp. So far, in vitro studies have not identified a biochemical role for WRNp in NHEJ, but there is a good deal of effort on resolution of this problem in various laboratories at this time.

The genome instability in WS has been suggested to arise from a failure to resolve alternate DNA structures. Sequences prone to form triple helices are abundant in the human genome. This laboratory has tested the ability of WRN helicase to unwind such structures, and we have found that the enzyme is able to unwind a 3' tailed triple-helix DNA substrate in a reaction dependent on nucleoside triphosphate hydrolysis[24]. It is possible that triplex structures are more persistent in WS cells, and this may be a basis for the variegated translocation mosaicism seen in WS cells.

During recombinational events such as DNA repair of lesions that include both DNA strands (e.g., cross-links), intermediate structures are formed in DNA. One such intermediate is the Holliday structure, where homologous DNA molecules exchange strands. The 3' end of the newly synthesized DNA strand invades the daughter duplex structure of the intact DNA molecule. These structures can be generated experimentally in vitro, and the mechanism of their resolution can be examined. In such an experiment, it appears that the purified WRN enzyme 
resolves this structure[12]. WRNp binds to a single-stranded site in the Holliday structure where the ruvA protein also binds. This unwinding is ATP-dependent, suggesting that it is due to the helicase activity of WRNp. Recent studies indicate that WRN helicase efficiently unwinds Holliday junctions[25], suggesting a direct role of WRNp in recombination.

\section{Werner Syndrome Functions and Normal Aging}

The WRNp is a member of the RecQ family of helicases, to which the yeast Sgs1 and human Bloom proteins also belong. However, WRNp is unusual in that it is the only human member of this family of proteins that contains an exonuclease activity in addition to the helicase function. Until very recently, there has been no information about WRNp interactions or about in which protein complexes it participates. In the above, we have discussed various protein interactions involving WRNp; and, while the interactions are listed in Table 2, the mapping of some of these protein binders to WRNp is shown in Fig. 1. The implications of these interactions are that WRNp probably participates in all the pathways listed in Fig. 2 and discussed above. WRNp has attracted a lot of interest, and information is accumulating rapidly about its roles. Soon we should know much more about its interactions and complex formation.

Recent studies suggest that WRN may also participate in pathways at telomeric ends. WS cells display some defects in telomere metabolism, including increased rates of telomere shortening[26] and deficiencies in repair at telomeres[27]. Furthermore, expression of telomerase in WS cell lines prevents premature replicative senescence[28] and reduces hypersensitivity to 4NQO[29]. There is also recent evidence for WRN localization at telomeric ends in some human fibroblast cell lines in vivo[30]. In addition, the WRN yeast homologue Sgs1 was shown to participate in a telomerase-independent mechanism of telomere lengthening in yeast[30]. Therefore, WRN may function at telomeres by resolving secondary structure in order to allow access to replication, repair, and/or telomere-lengthening machinery.

Werner syndrome is a segmental progeria. This means that the disease is associated with a large number of clinical features that are seen in normal aging at a later stage in life. Whereas WS cannot be equated with the normal aging process, it is of significant interest that a mutation in one gene can lead to so many signs of aging. These include the increased frequency of age-associated diseases such as cancers and type II diabetes, and they include a large spectrum of phenotypic changes associated with the normal aging process[31]. Thus, insight into the molecular pathways involving the WRNp is bound to shed important light on the normal aging process and on why aging is accompanied by such a high level of associated disease.

\section{COCKAYNE SYNDROME}

Cockayne syndrome (CS) is a rare, inherited human genetic disease categorized as a segmental progeria. Affected individuals suffer from postnatal growth failure resulting in cachectic dwarfism, photosensitivity, skeletal abnormalities, mental retardation, progressive neurological degeneration, retinopathy, cataracts, and sensorineural hearing loss[32,33]. Two complementation groups, CS-A and CS-B, have been identified, and the corresponding genes have been cloned[34,35]. The cellular phenotype of CS includes increased sensitivity to a number of DNAdamaging agents, including UV radiation, ionizing radiation, and hydrogen peroxide[36,37].

Nucleotide excision repair (NER) is a complex process that removes and repairs many types of DNA lesions. NER has two subpathways: (1) the transcription-coupled repair (TCR) pathway and (2) the global genome repair (GGR) pathway. The TCR pathway repairs lesions in the 


\section{Werner binding proteins}

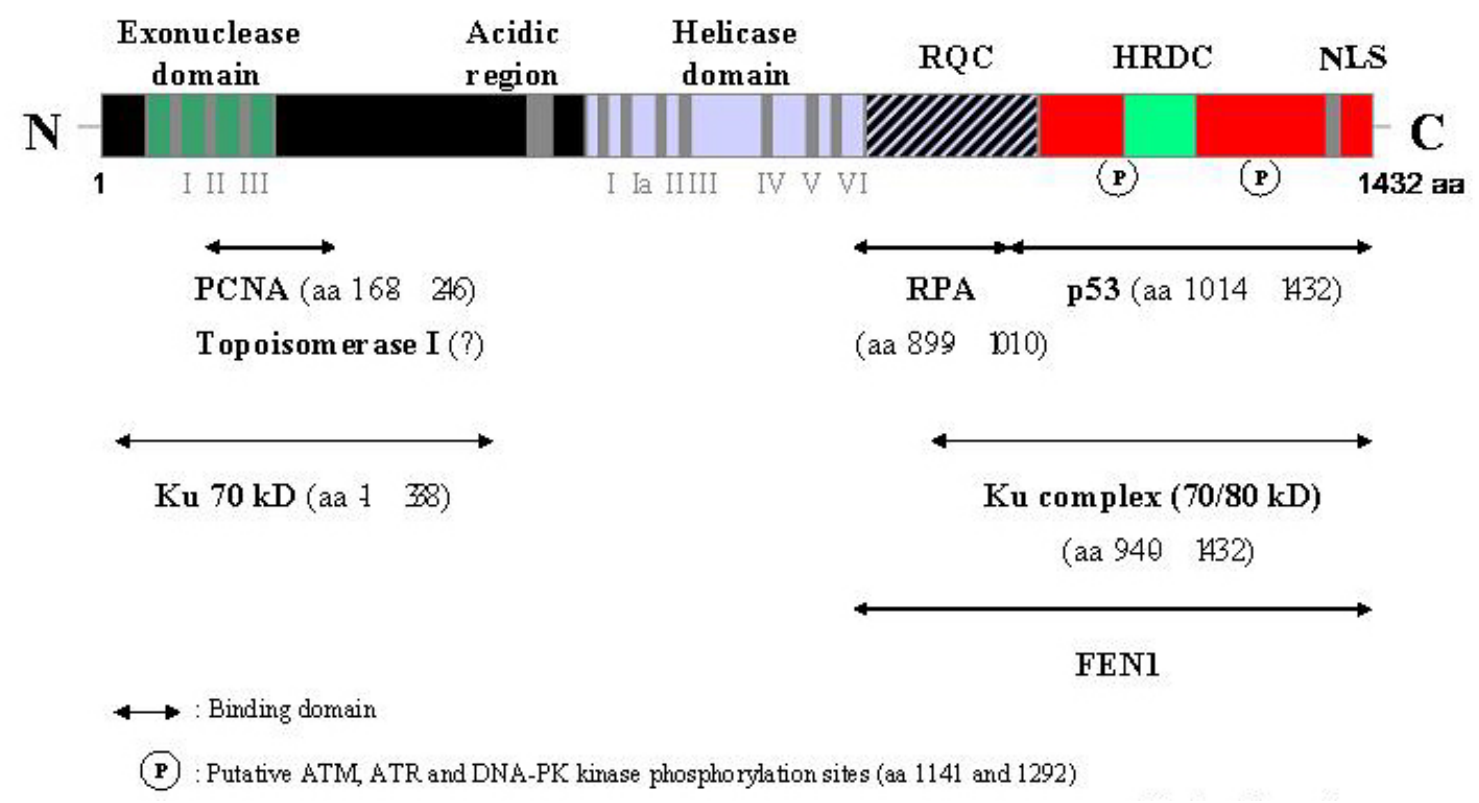

FIGURE 1. Werner protein interactors.

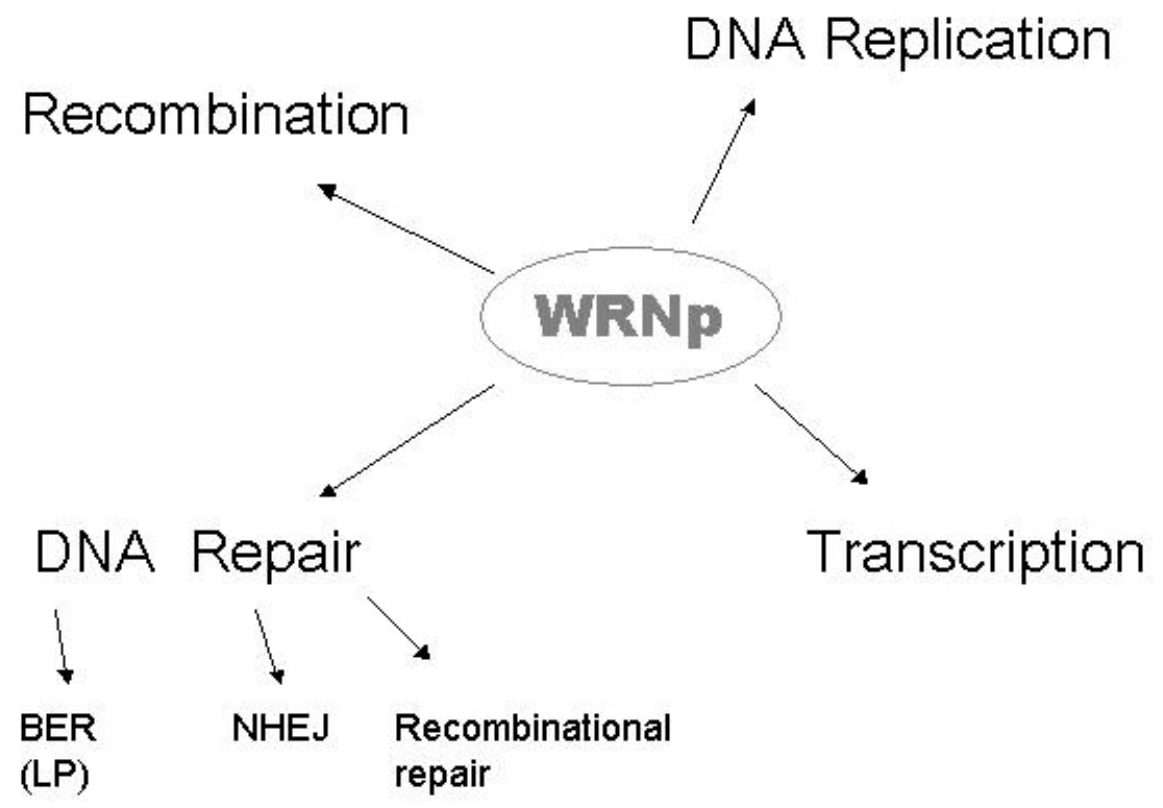

FIGURE 2. Processes in which Werner protein participates. 
transcribed strand of transcriptionally active genes and is dependent on RNA polymerase II (RNA pol II) $[38,39]$. The GGR pathway removes lesions from genes that are transcriptionally active or inactive. CS cells are defective in TCR but proficient in GGR of UV-induced DNA damage[40]. A characteristic feature of CS cells is that they do not recover the ability to efficiently synthesize RNA after UV damage[41]; this phenotype is consistent with a defect in TCR.

The CSA and CSB genes have been cloned and their products characterized biochemically. The CSA gene product is a 44-kDa protein that belongs to the "WD repeat" family of proteins[35]. Members of this protein family are structural and regulatory proteins, but they do not have enzymatic activity. The CSB gene product is a 168-kDa protein[34] that belongs to the SWI/SNF family of proteins, which are DNA and RNA helicases with seven conserved sequence motifs[42]. In addition, CSB has an acidic amino acid stretch, a glycine-rich region, and two putative NLS sequences. CSB is a DNA-stimulated ATPase but is not able to unwind DNA in a conventional strand-displacement assay[43,44]. The human CSB cDNA complements the UV sensitivity and the delay in RNA synthesis recovery when transfected into the human CS-Bdeficient cell line CS1AN.S3.G2[34] or the hamster CS-B-deficient cell line UV61[34]. Genespecific TCR repair is also recovered when the human CSB gene is transfected into UV61 cells[45,46].

The precise molecular role of CSB is not clear at present. CSB may facilitate repair of active genes by recruiting DNA repair proteins to actively transcribed regions. In vitro, CSB exists in a quaternary complex with RNA pol II, DNA, and the RNA transcript, and ATP hydrolysis is required to form this complex[44]. This quaternary complex recruits another molecular complex that includes the transcription factor IIH (TFIIH) core subunits p62 and XPB[47]. TFIIH is a complex factor thought to promote local DNA unwinding during transcription initiation by RNA pol II and promoter escape, as well as in NER[48,49,50,51,52]. Coimmunoprecipitation studies demonstrate that XPG and CSB proteins interact[53]. XPG interacts with multiple components of TFIIH[53], and it is an endonuclease that plays a role in NER. In vitro, CSB interacts with CSA and with the NER damage recognition factor XPA[35,43]. These protein interactions support the hypothesis that CSB participates directly in TCR.

It is also possible that CSB indirectly stimulates TCR by facilitating transcription. Members of the SWI/SNF family are involved in transcription regulation, chromatin remodeling, and DNA repair, including such actions as disruption of protein-protein and protein-DNA interactions (reviewed in[54]). The CSB gene product could have a similar function. In fact, it is still a matter of debate whether CS is due to a primary defect in transcription or DNA repair[55,56]. The basal transcription level is lower in human CS-B lymphoblastoid cells and fibroblasts than in normal cells, even without exposure to DNA-damaging agents[57]. This transcription defect is complemented by normal cell extracts in vitro or by the wild-type CSB gene in vivo. In a reconstituted system, purified CSB protein enhances the rate of transcription by RNA pol II[58], suggesting that CSB may indirectly stimulate TCR by facilitating the process of transcription[58]. Thus, CSB may be a transcription elongation factor and a repair-coupling factor acting at the site of RNA pol II-blocking lesions, and the CS phenotype may arise from deficiencies in both transcription and DNA repair. The biological function of CSB in these different pathways may be mediated by distinct functional domains of the protein.

As described above, it is well-established that the CSB phenotype involves a defect in TCR of UV-induced DNA damage. However, evidence also suggests that TCR of oxidative damage may be affected by CSB[59]. Hydrogen peroxide and ionizing radiation induce a large variety of DNA damage, including oxidatively damaged bases and single- and double-strand DNA breaks. 
TABLE 3

DNA Repair Transcription, and Chromatin Structure in Cockayne Syndrome (CS)

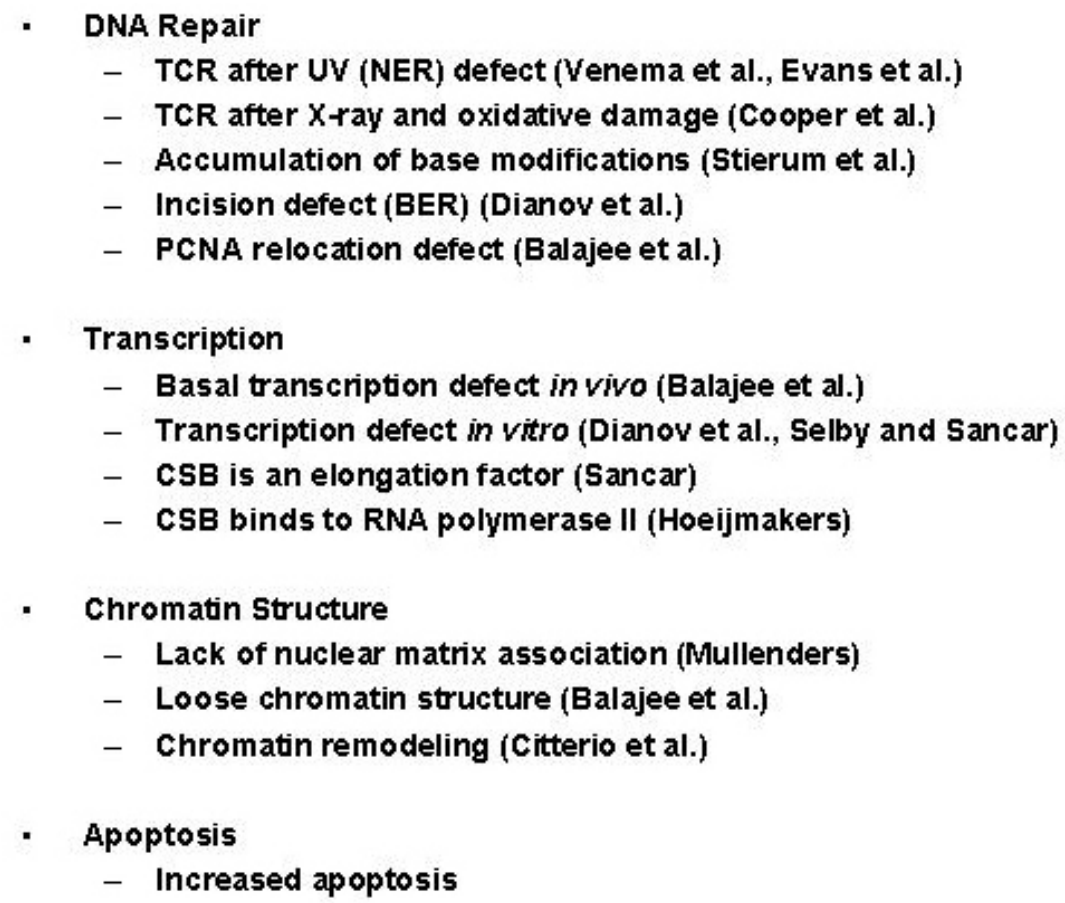

It has been shown that primary CS-B cells are slightly more sensitive to $\gamma$-irradiation; and in addition, they are defective in strand-specific repair of ionizing radiation and hydrogen peroxideinduced thymine glycol[36,37]. Previously, this laboratory showed that the ability of CS-B cell extracts to carry out incision of 8-oxoguanine lesions in vitro is $50 \%$ of normal; in contrast, incision of uracil and thymine glycol were normal[60]. 8-Oxoguanine is a base modification caused by oxidative stress from environmental agents and from endogenous metabolic processes, and it is repaired mainly via base excision repair (BER)[61,62]. Further recent studies from this laboratory show that the CSB protein is involved in BER. We have established stably transfected human cell lines in which functional domains of the CSB gene have been mutated[63]. When certain helicase motifs are disrupted, there is a cellular defect in the incision of DNA containing 8-oxoG in cell extracts[63].

Understanding the exact role of CSB is quite challenging. Some of the cellular deficits, which also give clues to the pathways that involve CSB, are listed in Table 3. We are convinced that this important protein participates not only in transcription-coupled repair but also in BER, and that it also plays a role in transcription.

\section{REFERENCES}

1. Yu, C.E., Oshima, J., Fu, Y.H., Wijsman, E.M., Hisama, F., Alisch, R., Matthews, S., Nakura, J., Miki, T., Ouais, S., Martin, G.M., Mulligan, J., and Schellenberg, G.D. (1996) Positional cloning of the Werner's syndrome gene. Science 272, 258-262.

2. Gray, M.D., Shen, J.C., Kamath-Loeb, A.S., Blank, A., Sopher, B.L., Martin, G.M., Oshima, J., and Loeb, L.A. (1997) The Werner syndrome protein is a DNA helicase. Nat. Genet. 17, 100-103.

3. Suzuki, N., Shimamoto, A., Imamura, O., Kuromitsu, J., Kitao, S., Goto, M., and Furuichi, Y. (1997) DNA helicase activity in Werner's syndrome gene product synthesized in a baculovirus system. Nucleic Acids Res. 25, 2973-2978. 
4. Huang, S., Li, B., Gray, M.D., Oshima, J., Mian, I.S., and Campisi, J. (1998) The premature ageing syndrome protein, WRN, is a 3'-->5' exonuclease. Nat. Genet. 20, 114-116.

5. Kamath-Loeb, A.S., Shen, J.C., Loeb, L.A., and Fry, M. (1998) Werner Syndrome Protein. II. Characterization of the integral 3' --> 5' DNA exonuclease. J. Biol. Chem. 273, 34145-34150.

6. Shen, J.C., Gray, M.D., Oshima, J., Kamath-Loeb, A.S., Fry, M., and Loeb, L.A. (1998) Werner Syndrome Protein. I. DNA helicase and DNA exonuclease reside on the same polypeptide. J. Biol. Chem. 273, 3413934144.

7. Fukuchi, K., Martin, G.M., and Monnat, R.J. (1989) Mutator phenotype of Werner syndrome is characterized by extensive deletions. Proc. Natl. Acad. Sci. U. S. A. 86, 5893-5897.

8. Poot, M., Hoehn, H., Runger, T.M., and Martin, G.M. (1992) Impaired S-phase transit of Werner syndrome cells expressed in lymphoblastoid cells. Exp. Cell Res. 202, 267-273.

9. Poot, M., Yom, J.S., Whang, S.H., Kato, J.T., Gollahon, K.A., and Rabinovitch, P.S. (2001) Werner syndrome cells are sensitive to DNA cross-linking drugs. FASEB J. 15, 1224-1226.

10. Bohr, V.A., Souza-Pinto, N., Nyaga, S., Dianov, G., Kraemer, K.H., Seidman, M.M., and Brosh, Jr., R.M. (2001) DNA repair and mutagenesis in Werner Syndrome. Environ. Mol. Mutagen., in press.

11. Hanada, K., Ukita, T., Kohno, Y., Saito, K., Kato, J., and Ikeda, H. (1997) RecQ DNA helicase is a suppressor of illegitimate recombination in Escherichia coli. Proc. Natl. Acad. Sci. U. S. A. 94, 3860-3865.

12. Constantinou, A., Tarsounas, M., Karow, J.K., Brosh, Jr., R.M., Bohr, V.A., Hickson, I.D., and West, S.C. (2000) The Werner's Syndrome Protein (WRN) translocates Holliday Junctions in vitro and co-localises with RPA upon replication arrest. EMBO Rep. 1, 80-84.

13. Ogburn, C.E., Oshima, J., Poot, M., Chen, R., Gollahon, K.A., Rabinovitch, P.S., and Martin, G.M. (1997) An apoptosis-inducing genotoxin differentiates heterozygotic carriers for Werner helicase mutations from wild-type and homozygous mutants. Hum. Genet. 101, 121-125.

14. Webb, D.K., Evans, M.K., and Bohr, V.A. (1996) DNA repair fine structure in Werner's syndrome cell lines. Exp. Cell Res. 224, 272-278.

15. Balajee, A.S., Machwe, A., May, A., Gray, M.D., Oshima, J., Martin, G.M., Nehlin, J.O., Brosh, Jr., R.M., Orren, D.K., and Bohr, V.A. (1999) The Werner syndrome protein is involved in RNA polymerase II transcription. Mol. Biol. Cell 10, 2655-2668.

16. Brosh, Jr., R.M., Orren, D.K., Nehlin, J.O., Ravn, P.H., Kenny, M.K., Machwe, A., and Bohr, V.A. (1999) Functional and physical interaction between WRN helicase and human replication protein A. J. Biol. Chem. 274, 18341-18350.

17. Spillare, E.A., Robles, A.I., Wang, X.W., Shen, J.C., Yu, C.E., Schellenberg, G.D., and Harris, C.C. (1999) p53-mediated apoptosis is attenuated in Werner syndrome cells. Genes Dev. 13, 1355-1360.

18. Brosh, Jr., R.M., Karmakar, P., Sommers, J.A., Yang, Q., Wang, X.W., Spillare, E.A., Harris, C.C., and Bohr, V.A. (2001) p53 Modulates the exonuclease activity of Werner syndrome protein. J. Biol. Chem. 276, 35093-35102.

19. Lebel, M., Spillare, E.A., Harris, C.C., and Leder, P. (1999) The Werner syndrome gene product co-purifies with the DNA replication complex and interacts with PCNA and topoisomerase I. J. Biol. Chem. 274, 37795-37799.

20. Szekely, A.M., Chen, Y.H., Zhang, C., Oshima, J., and Weissman, S.M. (2000) Werner protein recruits DNA polymerase delta to the nucleolus. Proc. Natl. Acad. Sci. U. S. A. 97, 11365-11370.

21. Kamath-Loeb, A.S., Johansson, E., Burgers, P.M., and Loeb, L.A. (2000) Functional interaction between the Werner Syndrome protein and DNA polymerase $\delta$. Proc. Natl. Acad. Sci. U. S. A. 97, 4603-4608.

22. Cooper, M.P., Machwe, A., Orren, D.K., Brosh, R.M., Ramsden, D., and Bohr, V.A. (2000) Ku complex interacts with and stimulates the Werner protein. Genes Dev. 14, 907-912.

23. Featherstone, C. and Jackson, S.P. (1999) DNA-dependent protein kinase gets a break: its role in repairing DNA and maintaining genomic integrity. Br. J. Cancer 80(Suppl. 1), 14-19.

24. Brosh, Jr., R.M., Majumdar, A., Desai, S., Hickson, I.D., Bohr, V.A., and Seidman, M.M. (2001) Unwinding of a DNA triple helix by the Werner and Bloom syndrome helicases. J. Biol. Chem. 276, 3024-3030.

25. Mohaghegh, P., Karow, J.K., Brosh, Jr., R.M., Bohr, V.A., and Hickson, I.D. (2001) The Bloom and Werner syndrome proteins are structure specific helicases. Nucleic Acids Res., in press.

26. Schulz, V.P., Zakian, V.A., Ogburn, C.E., McKay, J., Jarzebowicz, A.A., Edland, S.D., and Martin, G.M. (1996) Accelerated loss of telomeric repeats may not explain accelerated replicative decline of Werner syndrome cells. Hum. Genet. 97, 750-754.

27. Kruk, P.A., Rampino, N.J., and Bohr, V.A. (1995) DNA damage and repair in telomeres: relation to aging. Proc. Natl. Acad. Sci. U. S. A. 92, 258-262.

28. Wyllie, F.S., Jones, C.J., Skinner, J.W., Haughton, M.F., Wallis, C., Wynford-Thomas, D., Faragher, R.G., and Kipling, D. (2000) Telomerase prevents the accelerated cell ageing of Werner syndrome fibroblasts. Nat. Genet. 24, 16-17.

29. Hisama, F.M., Chen, Y.H., Meyn, M.S., Oshima, J., and Weissman, S.M. (2000) WRN or telomerase constructs reverse 4-nitroquinoline 1-oxide sensitivity in transformed Werner syndrome fibroblasts. Cancer Res. 60, 2372-2376. 
30. Johnson, F.B., Marciniak, R.A., McVey, M., Stewart, S.A., Hahn, W.C., and Guarente, L. (2001) The Saccharomyces cerevisiae WRN homolog Sgslp participates in telomere maintenance in cells lacking telomerase. EMBO J. 20, 905-913.

31. Martin, G.M. (1997) The pathobiology of the Werner syndrome. FASEB J. 11, A1449.

32. Nance, M. and Berry, S. (1992) Cockayne syndrome: review of 140 cases. Am. J. Med. Genet. 42, 68-84.

33. Friedberg, E.C. (1996) Cockayne syndrome - a primary defect in DNA repair, transcription, both or neither? BioEssays 18, 731-738.

34. Troelstra, C., van Gool, A., De Wit, J., Vermeulen, W., Bootsma, D., and Hoeijmakers, H.J. (1992) ERCC6, a member of a subfamily of putative helicases, is involved in Cockayne's syndrome and preferential repair of active genes. Cell 71, 939-953.

35. Henning, K., Li, L., Legerski, R., Iyer, N., McDaniel, L., Schultz, R., Stefanini, M., Lehmann, A., Mayne, L., and Friedberg, E. (1995) The Cockayne syndrome complementation group A gene encodes a WD-repeat protein which interacts with CSB protein and a subunit of the RNA pol II transcription factor IIH. Cell 82, 555-566.

36. Leadon, S.A. and Cooper, P.K. (1993) Preferential repair of ionizing radiation-induced damage in the transcribed strand of an active gene is defective in Cockayne syndrome. Proc. Natl. Acad. Sci. U. S. A. 90, 10499-10503.

37. Cooper, P.K., Nouspikel, T., Clarkson, S.G., and Leadon, S.A. (1997) Defective transcription-coupled repair of oxidative base damage in Cockayne syndrome patients from XP group G. Science 275, 990-993.

38. Leadon, S.A. and Lawrence, D.A. (1991) Preferential repair of DNA damage on the transcribed strand of the human metallothionein genes requires RNA polymerase II. Mutat. Res. 255, 67-78.

39. Christians, F.C. and Hanawalt, P.C. (1992) Inhibition of transcription and strand-specific DNA repair by $\alpha-$ amanitin in Chinese hamster ovary cells. Mutat. Res. 274, 93-101.

40. Venema, J., Mullenders, L.H., Natarajan, A.T., van Zeeland, A.A., and Mayne, L.V. (1990) The genetic defect in Cockayne syndrome is associated with a defect in repair of UV-induced DNA damage in transcriptionally active DNA. Proc. Natl. Acad. Sci. U. S. A. 87, 4707-4711.

41. Mayne, L.V. and Lehmann, A.R. (1982) Failure of RNA synthesis to recover after UV irradiation: and early defect in cells from individuals with Cockayne's syndrome and xeroderma pigmentosum. Cancer Res. 42, 1473-1478.

42. Gorbalenya, A.E., Koonin, E.V., Donchenko, A.P., and Blinov, V.M. (1989) Two related superfamilies of putative helicases involved in replication, recombination, repair and expression of DNA and RNA genomes. Nucleic Acids Res. 17, 4713-4730.

43. Selby, C.P. and Sancar, A. (1997) Human transcription-repair coupling factor CSB/ERCC6 is a DNAstimulated ATPase but is not a helicase and does not disrupt the ternary transcription complex of stalled RNA polymerase II. J. Biol. Chem. 272, 1885-1890.

44. Tantin, D., Kansal, A., and Carey, M. (1997) Recruitment of the putative transcription-repair coupling factor CSB/ERCC6 to RNA polymerase II elongation complexes. Mol. Cell Biol. 17, 6803-6814.

45. Orren, D.K., Dianov, G.L., and Bohr, V.A. (1996) The human CSB (ERCC6) gene corrects the transcription-coupled repair defect in the CHO cell mutant UV61. Nucleic Acids Res. 24, 3317-3322.

46. Brosh, Jr., R.M., Balajee, A.S., Selzer, R.R., Sunesen, M., De Santis, L.P., and Bohr, V.A. (1999) The ATPase domain but not the acidic region of Cockayne syndrome group B gene product is essential for DNA repair. Mol. Biol. Cell 10, 3583-3594.

47. Tantin, D. (1998) RNA polymerase II elongation complexes containing the Cockayne syndrome group B protein interact with a molecular complex containing the transcription factor IIH components xeroderma pigmentosum B and p62. J. Biol. Chem. 273, 27794-27799.

48. Schaeffer, L., Roy, R., Humbert, S., Moncollin, V., Vermeulen, W., Hoeijmakers, J.H., Chambon, P., and Egly, J.M. (1993) DNA repair helicase: a component of BTF2 (TFIIH) basic transcription factor. Science 260, 58-63.

49. Feaver, W.J., Svejstrup, J.Q., Bardwell, L., Bardwell, A.J., Buratowski, S., Donahue, T.F., Friedberg, E.C., and Kornberg, R.D. (1993) Dual roles of a multiprotein complex from S. cerevisiae in transcription and DNA repair. Cell 75, 1379-1387.

50. van Vuuren, A.J., Vermeulen, W., Ma, L., Weeda, G., Appeldoorn, E., Jaspers, N.G., Van der Eb, A.J., Bootsma, D., Hoeijmakers, J.H., Humbert, S., Schaeffer, L., and Egly, J.M. (1994) Correction of xeroderma pigmentosum repair defect by basal transcription factor BTF2 (TFIIH). EMBO J. 13, 1645-1653.

51. Schaeffer, L., Moncollin, V., Roy, R., Staub, A., Mezzina, M., Sarasin, A., Weeda, G., Hoeijmakers, J.H., and Egly, J.M. (1994) The ERCC2/DNA repair protein is associated with the class II BTF2/TFIIH transcription factor. EMBO J. 13, 2388-2392.

52. Drapkin, R., Reardon, J.T., Ansari, A., Huang, J.C., Zawel, L., Ahn, K., Sancar, A., and Reinberg, D. (1994) Dual role of TFIIH in DNA excision repair and in transcription by RNA polymerase II. Nature 368, 769-772.

53. Iyer, N., Reagan, M.S., Wu, K.J., Canagarajah, B., and Friedberg, E.C. (1996) Interactions involving the human RNA polymerase II transcription/nucleotide excision repair complex TFIIH, the nucleotide excision repair protein XPG, and Cockayne syndrome group B (CSB) protein. Biochemistry 35, 2157-2167. 
54. Pazin, M.J. and Kadonaga, J.T. (1997) SWI2/SNF2 and related proteins: ATP-driven motors that disrupt protein-DNA interactions? Cell 88, 737-740.

55. Van Gool, L., Meyer, R., Tobiasch, E., Cziepluch, C., Jauniaux, J.C., Mincheva, A., Lichter, P., Poirier, G.G., Bürkle, A., and Küpper, J.H. (1997) Overexpression of human poly(ADP-ribose) polymerase in transfected hamster cells leads to increased poly(ADP-ribosyl)ation and cellular sensitization to gamma irradiation. Eur. J. Biochem. 244, 15-20.

56. Van Gool, A.J., Citterio, E., Rademakers, S., Van Os, R., Vermeulen, W., Constantinou, A., Egly, J.M., Bootsma, D., and Hoeijmakers, J.H. (1997) The Cockayne syndrome B protein, involved in transcriptioncoupled DNA repair, resides in an RNA polymerase II-containing complex. EMBO J. 16, 5955-5965.

57. Balajee, A.S., May, A., Dianov, G.L., Friedberg, E.C., and Bohr, V.A. (1997) Reduced RNA polymerase II transcription in intact and permeabilized Cockayne syndrome group B cells. Proc. Natl. Acad. Sci. U. S. A. 94, 4306-4311.

58. Selby, C.P., Drapkin, R., Reinberg, D., and Sancar, A. (1997) RNA polymerase II stalled at a thymine dimer: footprint and effect of excision repair. Nucleic Acids Res. 25, 787-793.

59. Le Page, F., Klungland, A., Barnes, D.E., Sarasin, A., and Boiteux, S. (2000) Transcription coupled repair of 8-oxoguanine in murine cells: the ogg1 protein is required for repair in nontranscribed sequences but not in transcribed sequences. Proc. Natl. Acad. Sci. U. S. A. 97, 8397-8402.

60. Dianov, G., Bischoff, C., Sunesen, M., and Bohr, V.A. (1999) Repair of 8-oxoguanine in DNA is deficient in Cockayne syndrome group B cells. Nucleic Acids Res. 27, 1365-1368.

61. Lindahl, T. (1993) Instability and decay of the primary structure of DNA. Nature 362, 709-715.

62. Dianov, G., Bischoff, C., Piotrowski, J., and Bohr, V.A. (1998) Repair pathways for processing of 8oxoguanine in DNA by mammalian cell extracts. J. Biol. Chem. 273, 33811-33816.

63. Tuo, J., Muftuoglu, M., Chen, C., Jaruga, P., Selzer, R.R., Brosh, Jr., R.M., Rodriguez, H., Dizdaroglu, M., and Bohr, V.A. (2001) The Cockayne syndrome group B gene product is involved in general genome base excision repair of 8-hydroxyguanine in DNA. J. Biol. Chem. 276, 45772-45779.

This article should be referenced as follows:

Bohr, V.A. (2002) DNA-related pathways defective in human premature aging. TheScientificWorldJOURNAL 2, 12161226.

\section{Handling Editor:}

Efstathios S. Gonos, Associate Editor for Aging — a domain of TheScientificWorldJOURNAL. 

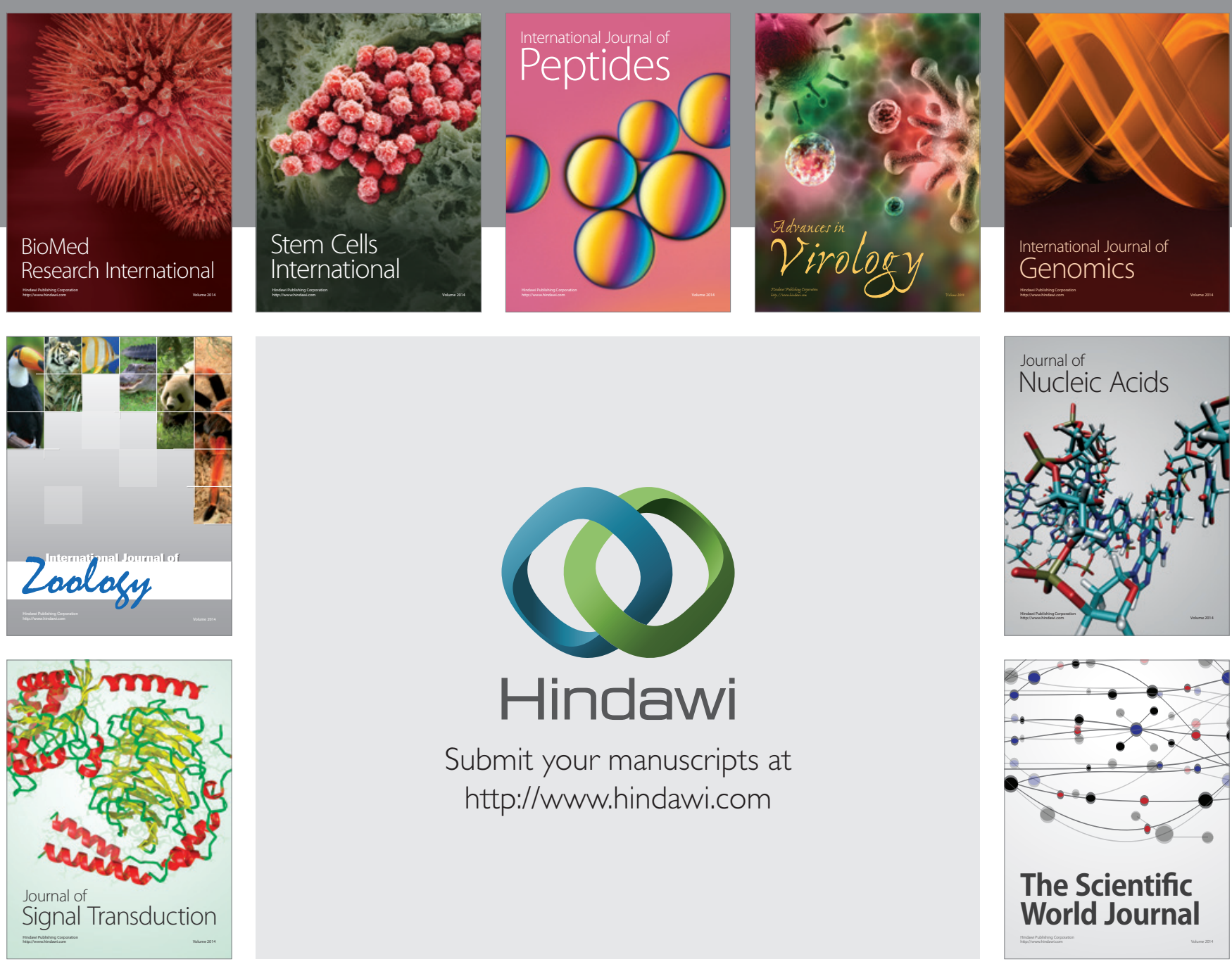

Submit your manuscripts at

http://www.hindawi.com
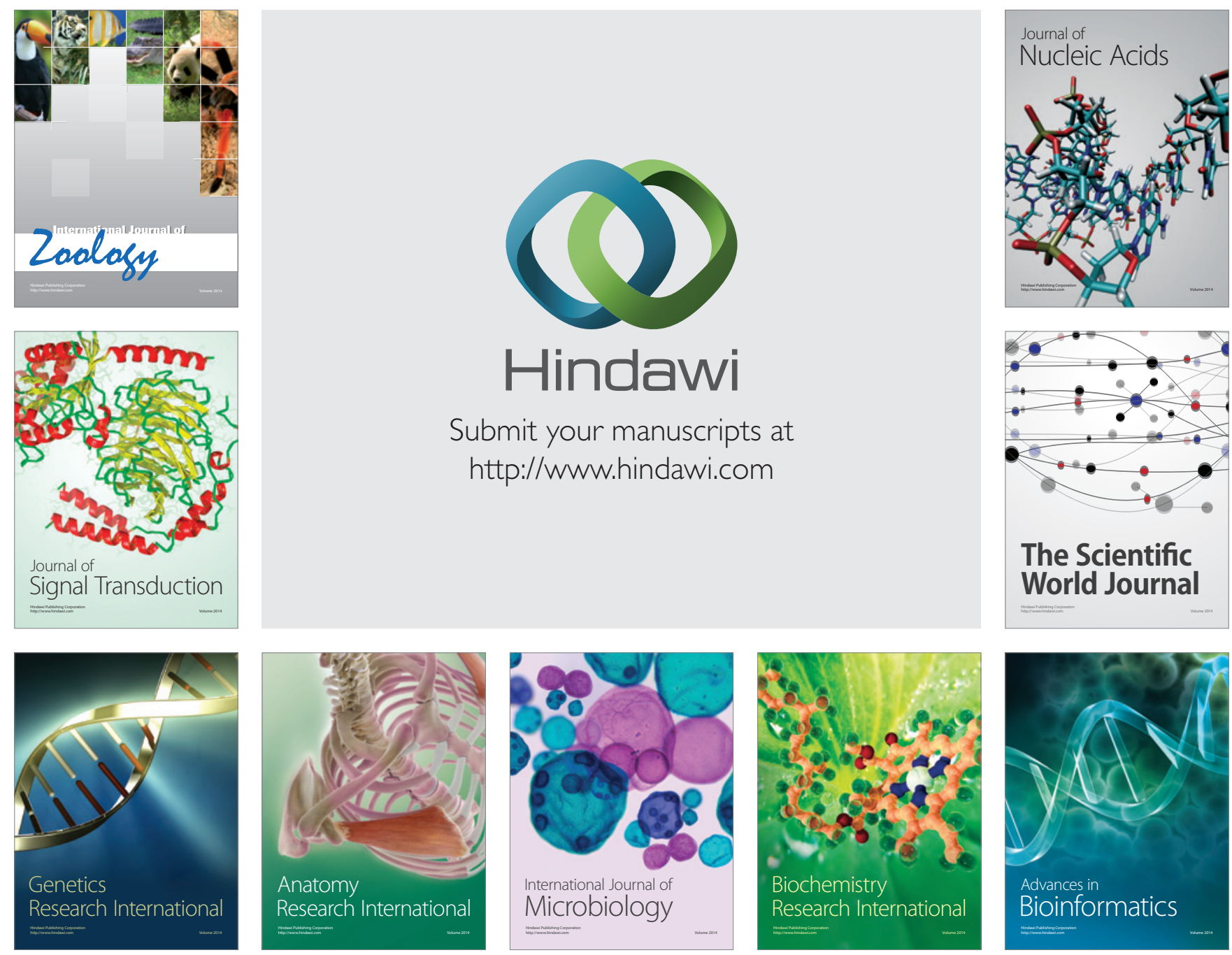

The Scientific World Journal
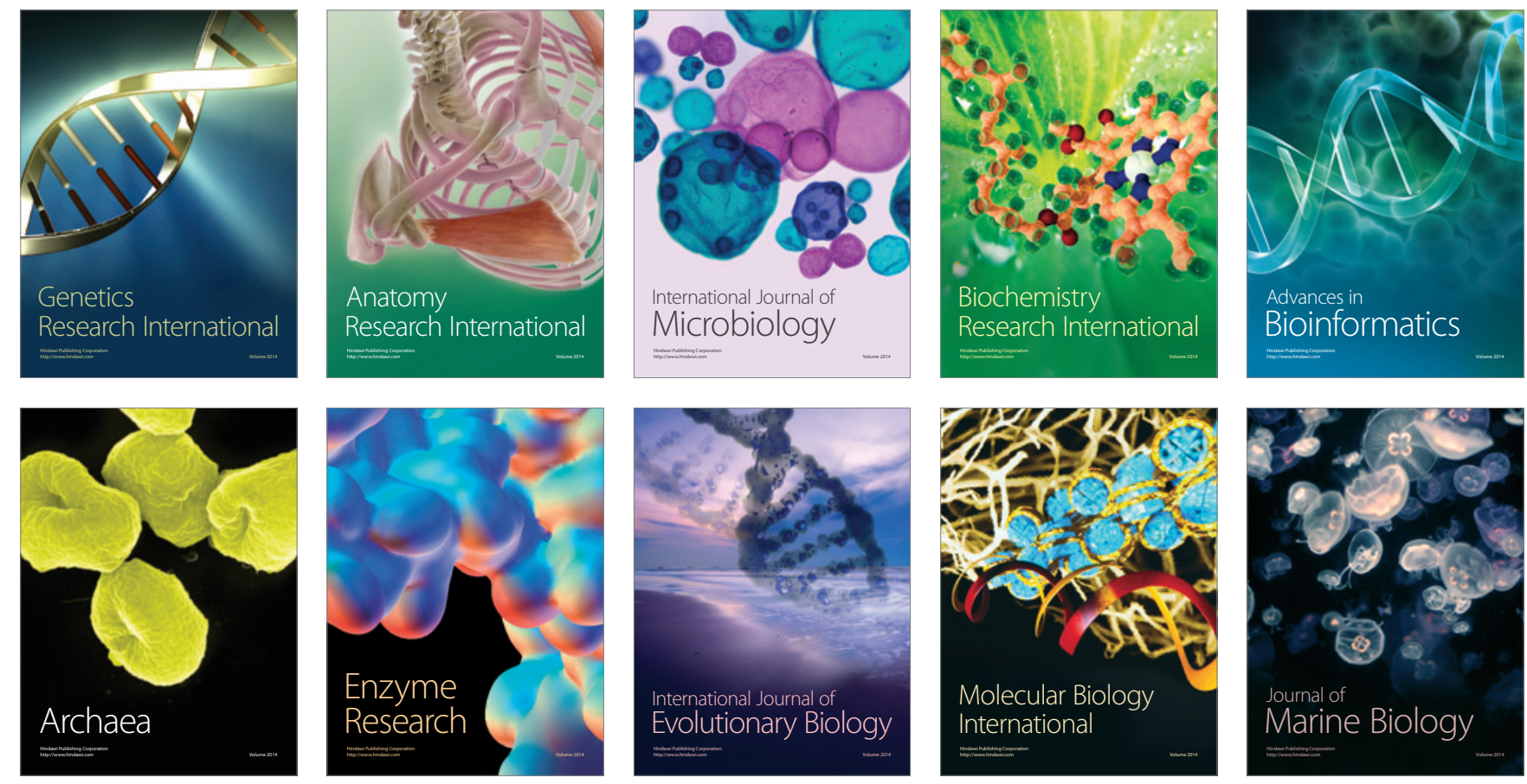